\title{
Topography and surface roughness of fluid resins used as bioprotectors of mini-implants
}

Rogério Lacerda-Santos ${ }^{1 *}$, Mirella de Fátima Liberato de Moura', Fabíola Galbiatti Carvalho², Hugo Lemes Carlo², Matheus Melo Pithon ${ }^{3}$, Bruno Alessandro Silva Guedes de Lima ${ }^{4}$ and Tibério Andrade dos Passos ${ }^{4}$

\author{
* Correspondence: \\ lacerdaorto@hotmail.com \\ ${ }^{1}$ Degree Program in Dentistry, \\ Federal University of Campina \\ Grande, Av. dos Universitários, s/n, \\ Santa Cecília, 58700-970 Patos, PB, \\ Brazil \\ Full list of author information is \\ available at the end of the article
}

\begin{abstract}
Objective: The focus of this study was to test the hypothesis that there is difference between the surface roughness and topography of flow resins used as bioprotective materials of orthodontic mini-implants. Thirty test specimens $(5 \mathrm{~mm} \times 3 \mathrm{~mm})$ of flow resins were used, divided into 3 groups $(n=10)$ : Group W (Wave), Group TC (Top Comfort) and Group F (Filtek Z350 XT). Topographic analysis was performed by scanning electron microscopy (SEM) and surface roughness measurement by Atomic Force Microscopy (AFM). One-way analysis of variance ANOVA followed by the Tukey post hoc test were used for statistical evaluation $(p<.05)$. By SEM, Group W presented a surface that was not very homogeneous with inorganic particles of up to $5 \mu \mathrm{m}$; in a similar manner and with a larger number of particles, Group TC was shown to have particles close to $3 \mu \mathrm{m}$ in size. Whereas, Group F presented a more homogeneous and regular surface with few inorganic particles of $1 \mu \mathrm{m}$. AFM demonstrated that there was a significantly higher degree of surface roughness in Group W, which showed statistically significant difference from Group $F(p=.007)$, and no significant difference between Group TC and the other groups ( $p>05$ ). The hypothesis was partially accepted; it could be affirmed that the flow resin Filtek Z350 presented a lower degree of surface roughness, and had smaller and more uniformly distributed inorganic particles when compared with the Wave and Top Comfort resins.
\end{abstract}

Keywords: Resins; Surface roughness; Topography

\section{Background}

The majority of resins used in orthodontics [1-4] have a smaller quantity of load than the traditional resin composite [5-9]. Recently, fluid dental resins have been used in orthodontics, with the purpose of providing bioprotection over mini-implants to diminish the areas of traumas on the adjacent gingival tissues [10]. There resins present a high level of fluidity and low modulus of elasticity [11], which, theoretically, dissipates the stress generated by thermal and masticatory tensions to a better extent [12]. In spite of the difficulty of handling them, due to their viscosity, they may be applied as a coating material in sites that are difficult to access, because of their fluidity $[13,14]$.

On the other hand, the question has arisen about whether the topography and surface roughness of these resins could favor the retention of food and pathogenic bacteria [10], because of the heterogeneous nature of their resin components, such as the type, size, shape and composition of the load particles, quality and quantity of the 
organic component, type of bond and polymerization system $[11,15,16]$ which may also generate or aggravate a peri-implant [10] inflammation [17].

Apart from the physical properties of the material, regular tooth brushing may increase the roughness on the surface of these fluid resins, making them more propense to biofilm accumulation [18] and gingival tissue inflammation [11,19]. Taken in conjunction, the physical and mechanical $[11,15]$ properties of flow resins are aligned with the notion that the proximity of mini-implants [10] to the gingiva and oral tissues, make the surface topography and roughness important items to consider in the selection of these resins. Therefore, the focus of this study was to test the hypothesis that there are differences between the surface roughness and topography of flow resins used as bioprotective materials of orthodontic mini-implants.

\section{Methods}

Three flow resins were evaluated with regard to surface topography and roughness, and were divided into 3 groups: Group W (Wave), Group TC (Top Comfort) and Group F (Filtek Z350 XT) (Table 1). Thirty specimens ( $\mathrm{n}=10$ for each group) were fabricated using silicone molds measuring $5 \mathrm{~mm}$ in diameter and $3 \mathrm{~mm}$ high. The material was inserted directly into the mold with the aid of the specific applicators of each resin, as indicated by the manufacturers, thus preventing bubble formation. The specimen surfaces were covered with glass slides under slight finger pressure, in order to flatten the surface of the material on both sides.

All the materials were light polymerized for 40 seconds on each side by a single operator, using a LED appliance (Radii, SDI, Baywater, Victoria, Australia) fixed on a rod to guarantee that the distance between the specimens remained constant, using a light intensity of $1000 \mathrm{mw} / \mathrm{cm}^{2}$, regularly calibrated with a radiometer (Model 100, Demetron Research Corporation, Danbury, CT, USA).

\section{Surface topography}

Fifteen flow resin specimens ( $\mathrm{n}=5$ per group) were evaluated with regard to surface topography, by scanning electron microscopy (SEM) (JSM-6360LV, Jeol, Tokyo, Japan), at different magnifications (10-1000 times) using the same tension of $20 \mathrm{kV}$ in an acquisition time of $100 \mathrm{~s}$ for qualitative evaluation of the micromorphological characteristics of the flow resins. Five random fields were captured by SEM in each specimen at magnification of 1000 times in all groups evaluated for the surface microanalysis, as regards the presence and size of inorganic load particles of the resins.

Table 1 Composition of the tested resins

\begin{tabular}{lllll}
\hline Groups & Resins & Composition & Manufacturer & Lot \\
\hline $\mathbf{F}$ & Filtek & $\begin{array}{l}\text { 35\% by weight of BisGMA, TEGMA, ytterbium fluoride, } \\
\text { dimethacrylate-functionalized polymer and 65\% } \\
\text { by weight of ceramic inorganic particles and } \\
\text { silane-treated silica and titanium dioxide. }\end{array}$ & $\begin{array}{l}3 \text { M/Espe, St. } \\
\text { Paul, MN, USA }\end{array}$ & N376841 \\
TC & $\begin{array}{l}\text { Top } \\
\text { comfort }\end{array}$ & $\begin{array}{l}\text { 60\% by weight of methacrylate monomers } \\
\text { (BisGMA, UDMA and TEGMA), stabilizer, camphorquinone, } \\
\text { co-initiator, pigments and 40\% by weight of boron-aluminum- } \\
\text { silicate glass inorganic particles and nanoparticulate silica. }\end{array}$ & $\begin{array}{l}\text { FGM, Joinville, } 040112 \\
\text { SC, Brasil }\end{array}$ \\
W W Wave & $\begin{array}{l}\text { 35\% by weight multifunctional methacrylate ester and 65\% } \\
\text { by weight of inorganic particles. }\end{array}$ & $\begin{array}{l}\text { SDI, Bayswater, 110401 N } \\
\text { Vict, Australia }\end{array}$ \\
\hline
\end{tabular}




\section{Surface roughness}

Fifteen flow resin specimens ( $\mathrm{n}=5$ per group) were evaluated with regard to mean roughness $(\mathrm{Ra})$ which was randomly determined three times for each specimen. The Ra represents the arithmetic mean of the absolute values of the digitized surface. Three readouts in distinct areas of each specimen were taken by atomic force microscope (AFM; SPM-9600, Shimadzu, Kyoto, Japan) from each measurement of $1.5 \mathrm{~mm}$ of length on the surface. The specimens were fixed to the microscope on a metal support using adhesive tape. The surface morphology of the specimens was probed in "Contact Mode". The images were obtained with standard geometry from a silicon nitride micro-cantilever (radius of curvature $<10 \mathrm{~nm}$ ) (OMCL-TR, Olympus, Tokyo, Japan) and proved with an elastic constant of $0.15 \mathrm{~N} / \mathrm{m}$ and resonant frequency of $24 \mathrm{KHz}$. Images measuring $30 \mu \mathrm{m} \times 30 \mu \mathrm{m}$, with a resolution of $512 \times 512$ pixels and point of operation of $1.5 \mathrm{~V}$ were collected at a very low rate of digitization in order to obtain details about the structure of the material surfaces, to prevent damaging the tip. By means of Atomic Force Microscopy, quantitative and qualitative surface roughness data were obtained with precise details at a nanometric resolution [20].

Statistical analysis was performed with the statistical program BioEstat (version 5.0, Belém-PA, Brazil). The statistical method was chosen based on the verification of normal distribution and equality of variance evaluated by the Kolmogorov- Smirnov and Levene tests, respectively. One-way analysis of variance ANOVA followed by the Tukey multiple comparisons post hoc test were used, with confidence at a level of 0.05 of statistical significance.

\section{Results}

Group W presented an irregular and not very homogeneous surface with inorganic particles of up to $5 \mu \mathrm{m}$ in size (Figure 1A). A similar aspect could be noted in Group TC which, in spite of the larger number of particles observed, these did not exceed $3 \mu \mathrm{m}$ in size (Figure 1B). Contrary to Groups W and TC, Group F presented a significantly more regular and homogeneous surface with few visible inorganic particles, with a maximum size of $1 \mu \mathrm{m}$ (Figure 1C).

The surface roughness shown by Atomic Force Microscopy was of a significantly higher degree in Group W (Figure 2A), which showed statistically significant difference from Group F ( $\mathrm{p}=.007)$ (Figure $2 \mathrm{~B})$, and there was no significant difference between Group TC (Figure 2C) and the other groups evaluated (Table 2).

\section{Discussion}

The quantity of organic and inorganic particles in flow resins has a direct influence on their physical properties [11]. A resin that has a quantity larger than $80 \%$ of the inorganic phase, is more susceptible to compromise of its mechanical and physical properties, depending on the shape, size, chemical composition and distribution of the particles, making the material friable and giving it a rough surface [9], which potentiates biofilm retention $[18,19,21]$ and consequently gingival inflammation $[7,17]$.

In this study, the flow resin Wave demonstrated a more irregular and hardly homogeneous surface with inorganic particles of up to $5 \mu \mathrm{m}$ in size, which could accentuate the accumulation of microorganisms $[18,21]$ and the roughness could be potentiated by the surface abrasion resulting from tooth brushing [22] and exposure of the inorganic 


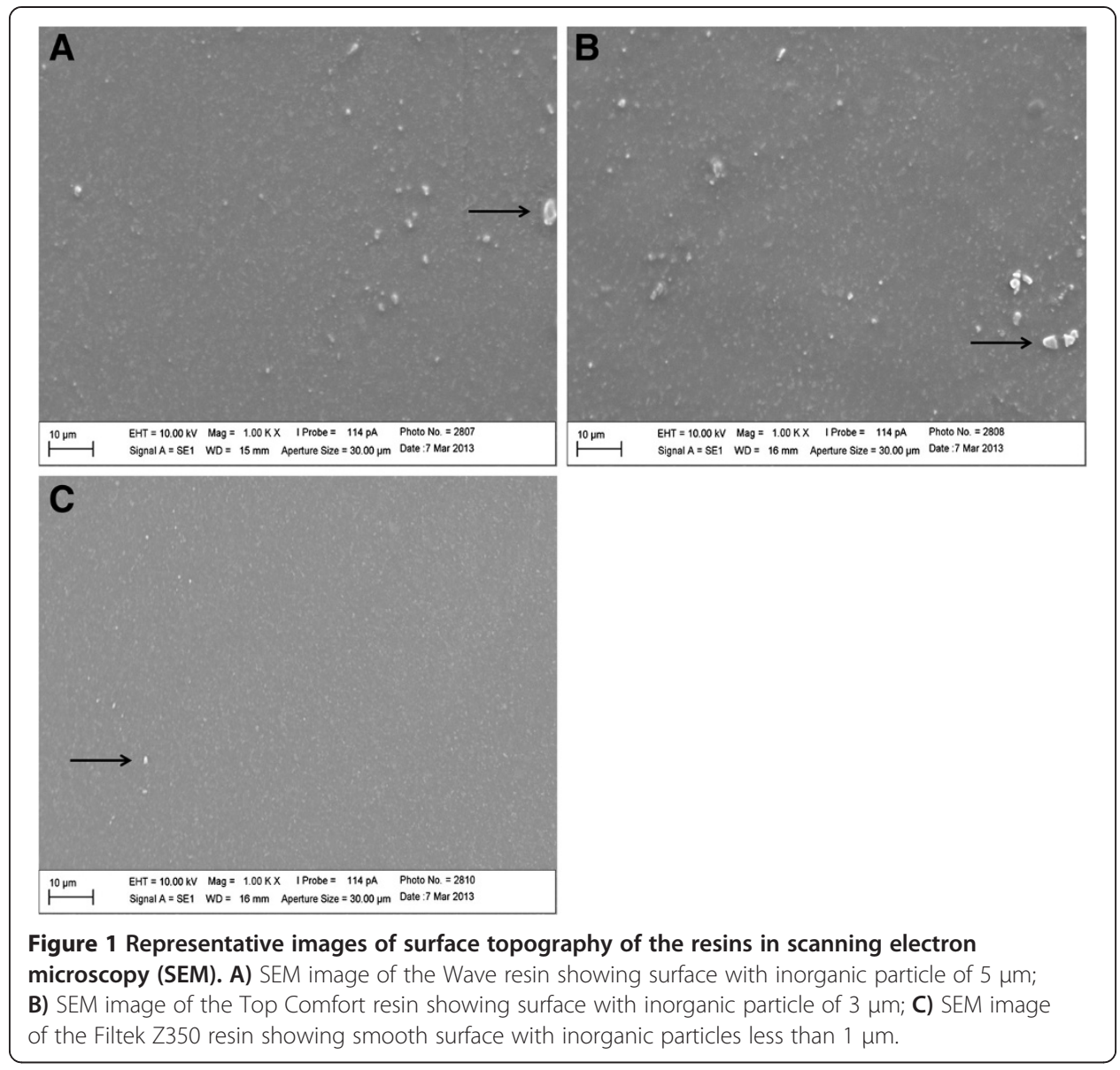

particles over the course of time [11]. The surface roughness of the flow resin Filtek Z350 presented the best results, with inorganic particles smaller than $1 \mu \mathrm{m}$ in size and a more homogeneous surface. These surface alterations are mainly related to the size and polishing of the inorganic particles of silica in the composition of these resins $[11,17,23]$.

The resin Filtek Z350 has 65\% of inorganic particles by weight, and so does the flow resin Wave, however, when observing the size of these inorganic particles by scanning electron microscopy, it was observed that the inorganic particles in resin Filtek Z350 were significantly smaller and more regular in comparison with those of resin Wave. The distribution of the pre-cured silica particles more uniformly distributed within the organic matrix of resin Filtek Z350 may help to reduce the quantity of organic matrix exposed to abrasion [11] during the time of clinical use.

On the other hand, the resin Top Comfort with $40 \%$ of inorganic particles by weight, demonstrated particles of an intermediate size $(3 \mu \mathrm{m})$ among the resins evaluated, although the particles found were smaller than those of resin Wave, the high quantity of organic component of the resin Top Comfort (60\%) makes it more propense to clinical wear when compared with the other resins tested. The size of inorganic particles as well as the quantity of organic load may influence the roughness $[11,13]$ which, according to some authors [11] even a less rough surface would not be free of abrasion, and wear of the organic fraction by regular brushing could be potentiated by substances such as mouthwashes [17] and bleaching agents [24,25], due to a probable elution of 

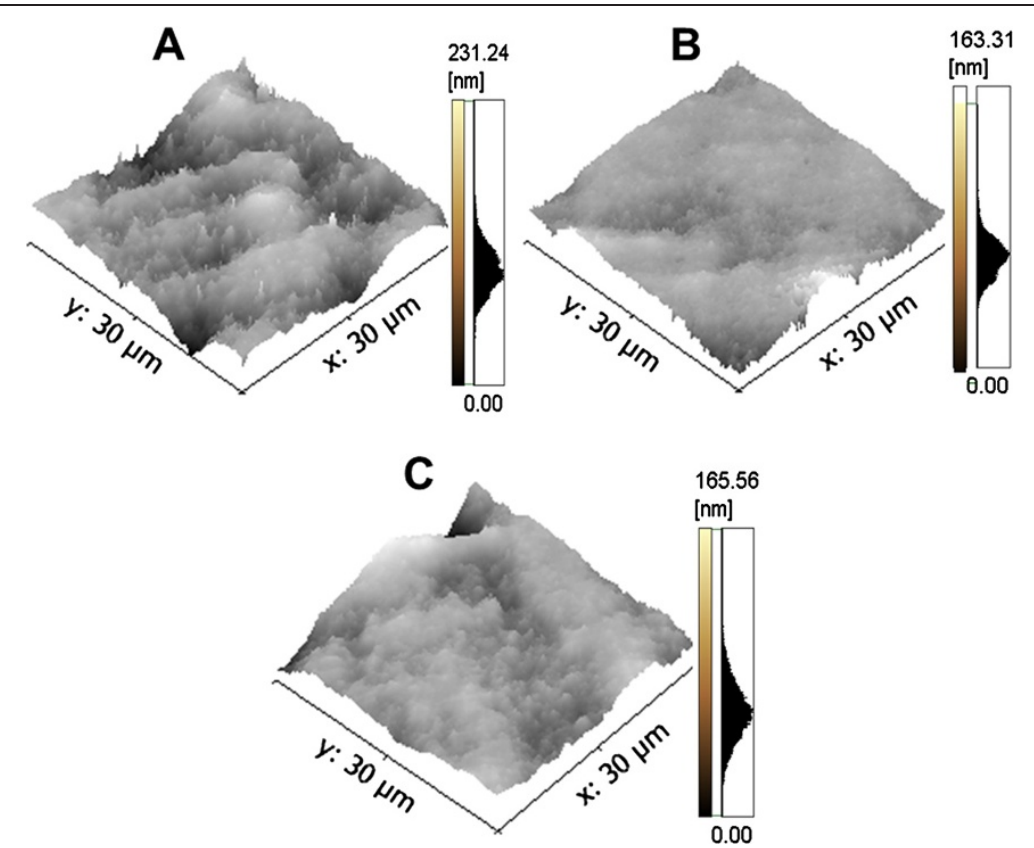

Figure 2 Representative images of surface roughness in Atomic Force Microscopy. A) Group W, B) Group F, and C) Group TC, showing the highest to the lowest roughness.

non-reacted components, such as residual monomers and the degrading effect on the polymeric chains [17]. This leads to the creation of spaces that vary according to the size, quantity of inorganic particles and inter-particle space [13], thus increasing the surface roughness $[11,18]$.

Fluid resins generally present an inorganic particle size ranging from $0.04-4 \mu \mathrm{m}$, so that the higher the percentage of the inorganic component, the greater the resistance to wear [11]. Although no statistical difference was detected between the resin Top Comfort and the other resins, a greater loss of mass appears to be probable of occurring over the time of clinical use, due to the lower concentration of inorganic particle by weight, and higher percentage of organic matrix in comparison with the resins Filtek Z350 and Wave.

The consequence of the difference in surface roughness observed in resin Wave may be the accumulation of biofilm [18,19] and debris, in addition to gingival irritation [10] and pigmentation $[19,23]$, and the same applies to the resin Top Comfort which, due to its large quantity of organic phase, would appear to have a potential for increase in roughness in the long term in the oral environment. Clinical studies [26,27] about resin composites have helped one to understand their behavior in the oral medium, in the

Table 2 Mean surface roughness (RA) of the flow resins

\begin{tabular}{lcc}
\hline Groups & Mean roughness $(\mathbf{n m})$ & DP* $^{*}$ \\
\hline $\mathrm{W}$ & $17.67^{\mathrm{A}}$ & 3.45 \\
$\mathrm{TC}$ & $13.58^{\mathrm{AB}}$ & 2.36 \\
$\mathrm{~F}$ & $9.83^{\mathrm{B}}$ & 1.16 \\
$\mathrm{P} \mathrm{valor}^{\dagger}$ & 0.007 & - \\
\hline
\end{tabular}

*SD = Standard deviation. ${ }^{\dagger} \mathrm{P}$ value: One-way ANOVA followed by Tukey multiple-comparison post-hoc test. Different letters express significant difference between groups $(p<.05)$. Letters $A, B$ in the same group indicates no statistical difference with the other groups. $(\mathrm{nm})=$ Nanometre. 
same way that clinical trials in orthodontic patients about fluid resins may help one to define the clinical applicability of fluid resins for use as bioprotective materials.

\section{Conclusions}

The hypothesis was partially accepted; it could be affirmed that the flow resin Filtek Z350 presented a lower degree of surface roughness, and had smaller and more uniformly distributed inorganic particles when compared with the Wave and Top Comfort resins, which presented a similar roughness, without significant difference between them.

\section{Competing interests}

The authors declare that they have no competing interests.

\section{Authors' contributions}

MFLM prepared the samples and wrote the paper. MMP planned the project and methodology and did the literature review. BASGL and TAP supervised the literature review and performed the topography and surface roughness test. HLC and FGC guided the conception idea, supervised the practical phase. RLS got the idea, the project planning, the methodology, the statistical analysis, and raised funds to do the study. All authors read and approved the final manuscript.

\section{Author details}

${ }^{1}$ Degree Program in Dentistry, Federal University of Campina Grande, Av. dos Universitários, s/n, Santa Cecília, 58700-970 Patos, PB, Brazil. ${ }^{2}$ Graduate Program in Dentistry, Federal University of Paraíba, Cidade Universitária, s/n, 58051-900 João Pessoa, PB, Brazil. ${ }^{3}$ Degree Program in Dentistry, Rua José Moreira Sobrinho, State University of Southwest Bahia, s/n, Jequiezinho, 45206-190 Jequié, BA, Brazil. ${ }^{4}$ Graduate Program in Materials Engineering, Federal University of Paraíba, Cidade Universitária, s/n, 58051-900 João Pessoa, PB, Brazil.

Received: 24 January 2014 Accepted: 3 February 2014

Published: 02 Oct 2014

\section{References}

1. Pithon MM, Santos RL, Martins FO, Romanos MTV, Araujo MT (2010) Evaluation of cytotoxicity and degree of conversion of orthodontic adhesives over different time periods cytotoxicity and degree of conversion. Mater Res 13:165-169

2. Santos RL, Sampaio GA, Carvalho FG, Pithon MM, Guenes GM, Alves PM (2013) Influence of degree of conversion on the biocompatibility of different composites in vivo. J Adhes Dent, 10.3290/j.jad.a29704

3. Gama ACS, Frota PHDB, Pereira AP, Costa JF, Bauer J (2005) Resinous materials used in bracket bonding: a literature review. Rev Ciênc Saúde 13:92-100

4. Santos RL, Pithon MM, Fernandes AB, Carvalho FG, Cavalcanti AL, Vaitsman DS (2013) Fluoride release/uptake from different orthodontic adhesives: a 30-month longitudinal study. Braz Dent J 24:410-414

5. Andrade AM, Moura SK, Reis A, Loguercio AD, Garcia EJ, Grande RH (2010) Evaluating resin-enamel bonds by microshear and microtensile bond strength tests: effects of composite resin. J Appl Oral Sci 18:591-598

6. Junior PCM, Cardoso RM, Magalhães BG, Guimarães RP, Silva CHV, Beatrice LCS (2011) Selecting correctly the composite resins. Int J Dent 10:91-96

7. Leinfelder KF (1997) New developments in resin restorative systems. J Am Dent Assoc 128:573-581

8. Lucey S, Lynch CD, Ray NJ, Burke FM, Hannigan A (2010) Effect of pre-heating on the viscosity and microhardness of a resin composite. J Oral Rehabil 37:278-282

9. Moszner N, Salz U (2001) New developments of polymeric dental composites. Prog Polymer Scien 26:535-576

10. Marquezan M, de Freitas AO, Nojima LI (2012) Miniscrew covering: an alternative to prevent traumatic lesions. Am J Orthod Dentofacial Orthop 141:242-244

11. Garcia FC, Wang L, D'Alpino PH, Souza JB, Araujo PA, Mondelli RF (2004) Evaluation of the roughness and mass loss of the flowable composites after simulated toothbrushing abrasion. Braz Oral Res 18:156-161

12. D'Attilio M, Traini T, Di lorio D, Varvara G, Festa F, Tecco S (2005) Shear bond strength, bond failure, and scanning electron microscopy analysis of a new flowable composite for orthodontic use. Angle Orthod 75:410-415

13. Bayne SC, Thompson JY, Swift EJ Jr, Stamatiades P, Wilkerson M (1998) A characterization of first-generation flowable composites. J Am Dent Assoc 129:567-577

14. Yazici AR, Ozgunaltay G, Dayangac B (2003) The effect of different types of flowable restorative resins on microleakage of class $\vee$ cavities. Oper Dent 28:773-778

15. St-Georges AJ, Swift EJ, Thompson JY, Heymann HO (2003) Irradiance effects on the mechanical properties of universal hybrid and flowable hybrid resin composites. Dent Mater 19:406-413

16. Bueno AL, Arrais CA, Jorge AC, Reis AF, Amaral CM (2011) Light-activation through indirect ceramic restorations: does the overexposure compensate for the attenuation in light intensity during resin cement polymerization? J Appl Oral Sci 19:22-27

17. Lucena MCM, Gomes RVS, Santos MCMS (2010) Evaluation of surface roughness of filtek Z350 3 M espe composite resin of viscosity low exposed to rinses with and without alcohol. Odontol Clin Cient 9:59-64

18. Bollen CM, Lambrechts P, Quirynen M (1997) Comparison of surface roughness of oral hard materials to the threshold surface roughness for bacterial plaque retention: a review of the literature. Dent Mater 13:258-269 
19. Lindquist B, Emilson CG (1990) Distribution and prevalence of mutans streptococci in the human dentition. J Dent Res 69:1160-1166

20. Medeiros IC, Brasil VL, Carlo HL, Santos RL, De Lima BA, De Carvalho FG (2013) In vitro effect of calcium nanophosphate and high-concentrated fluoride agents on enamel erosion: an AFM study. Int J Paediatr Dent, 10.1111/ipd.12046

21. Takahashi Y, Imazato S, Russell RR, Noiri Y, Ebisu S (2004) Influence of resin monomers on growth of oral streptococci. J Dent Res 83:302-306

22. Borges BCD, Barreto AS, Gomes CLR (2013) Preheating of resin-based flowable materials in a microwave device: a promising approach to increasing hardness and softening resistance under cariogenic challenge. Carbohydr Polym 8:558-568

23. Lee SY, Kim HC, Hur B, Park JK (2007) Surface roughness and color stability of various composite resins. J Kor Acad Cons Dent 32:542-549

24. Bodanezi A, de Bittencourt ME, Bodanezi RV, Zottis T, Munhoz EA, Carlini B Jr (2011) Surface modifications on aesthetically restored teeth following home bleaching with 16\% peroxide carbamide. Eur J Dent 5:157-162

25. El-Murr J, Ruel D, St-Georges AJ (2011) Effects of external bleaching on restorative materials: a review. J Can Dent Assoc 77:b59

26. Moncada G, Fernandez E, Martín J, Arancibia C, Mjor IA, Gordan W (2010) Increasing the longevity of restorations by minimal intervention: a two-year clinical trial. Oper Dent 33:258-264

27. Gallo JR, Burgess JO, Ripps AH (2010) Three-year clinical evaluation of two flowable composites. Quintessence Int 41:497-503

10.1186/2196-4351-2-21

Cite this article as: Lacerda-Santos et al:: Topography and surface roughness of fluid resins used as bioprotectors

of mini-implants. Applied Adhesion Science 2014, 2:21

Submit your manuscript to a SpringerOpen ${ }^{\odot}$ journal and benefit from:

- Convenient online submission

- Rigorous peer review

- Immediate publication on acceptance

- Open access: articles freely available online

- High visibility within the field

- Retaining the copyright to your article

Submit your next manuscript at $>$ springeropen.com 